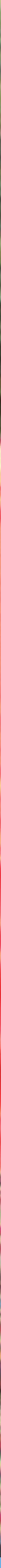

Implementation of guidance on dossier evaluation for the registration of pest control products in Kenya

Mechteld ter Horst, June Akinyi Aluoch, Maurice Wanyonyi Barasa, Saskia Bosman-Hoefakker, Jessica Broeders, Jacobijn van Etten, Esther de Jong, Paul N. Ngaruiya, Anne Steenbergh, Harold van der Valk, Githaiga Wagate, Sarah Muthoni Wambugu, Maureen Nekoye Waswa, Louise Wipfler 



\title{
Implementation of guidance on dossier evaluation for the registration of pest control products in Kenya
}

Mechteld ter Horst ${ }^{1}$, June Akinyi Aluoch ${ }^{4}$, Maurice Wanyonyi Barasa ${ }^{4}$, Saskia Bosman-Hoefakker ${ }^{2}$, Jessica Broeders ${ }^{2}$, Jacobijn van Etten ${ }^{2}$, Esther de Jong ${ }^{2}$, Paul N. Ngaruiya ${ }^{4}$, Anne Steenbergh ${ }^{2}$, Harold van der Valk ${ }^{3}$, Githaiga Wagate ${ }^{4}$, Sarah Muthoni Wambugu ${ }^{4}$, Maureen Nekoye Waswa ${ }^{4}$, Louise Wipfler ${ }^{1}$

\author{
1 Wageningen Environmental Research \\ 2 Dutch Board for the Authorisation of Plant Protection Products (Ctgb) \\ 3 Falconsult \\ 4 Kenyan Pest Control Products Board (PCPB)
}

This research was (partly) funded by the Dutch Ministry of Agriculture, Nature and Food Quality.

Wageningen Environmental Research

Wageningen, December 2019

Approved for publication:

M. de Potter 
Ter Horst, M.M.S., Aluoch, J.A., Barasa, M.W., Bosman-Hoefakker, S., Broeders, J., Van Etten, J., De Jong, E., Ngaruiya, P.N., Steenbergh, A., Van der Valk, H., Wagate, G., Wambugu S.M., Waswa, M.N., Wipfler, E.L. 2019. Implementation of guidance on dossier evaluation for the registration of pest control products in Kenya. Wageningen, Wageningen Environmental Research, Report 2980. 38 pp.; 5 fig.; 8 tab.; 15 ref.

This document describes suggestions for further steps that can be taken with regard to the evaluation of pest control products in Kenya. The document should be read together with the document describing proposed guidance on dossier evaluation for the registration of pest control products in Kenya and as such both contribute to a future complete pesticide evaluation manual for Kenya.

Both documents were developed within the Pesticide management initiative East African Region: Kenya (PEAR-Kenya) project. The project ran in the period 2016 - 2019 and was sponsored and supported by the Dutch Ministry of Agriculture, Nature and Food Quality and the Embassy of the Netherlands in Nairobi.

This document is intended to feed into discussions on further development of a complete pesticide evaluation manual for Kenya using the guidance mentioned as a starting point. Reflections on some of the methods proposed and also information on what is needed to implement the guidance developed in the project are provided. Additionally, suggestions for developing a framework for the risk assessment of aquatic organisms are given.

Keywords: Kenya, pest control, registration, Pest Control Products Board, risk assessment, human health, environment, pesticides, microbial pest control agent, metabolite

The pdf file is free of charge and can be downloaded at https://doi.org/10.18174/510075 or via the website www.wur.nl/environmental-research (scroll down to Publications - Wageningen Environmental Research reports). Wageningen Environmental Research does not deliver printed versions of the Wageningen Environmental Research reports.

2019 Wageningen Environmental Research (an institute under the auspices of the Stichting Wageningen Research), P.O. Box 47, 6700 AA Wageningen, The Netherlands, $\mathrm{T}+31$ (0)317 4807 00, www.wur.nl/environmental-research. Wageningen Environmental Research is part of Wageningen University \& Research.

- Acquisition, duplication and transmission of this publication is permitted with clear acknowledgement of the source.

- Acquisition, duplication and transmission is not permitted for commercial purposes and/or monetary gain.

- Acquisition, duplication and transmission is not permitted of any parts of this publication for which the copyrights clearly rest with other parties and/or are reserved.

Wageningen Environmental Research assumes no liability for any losses resulting from the use of the research results or recommendations in this report.

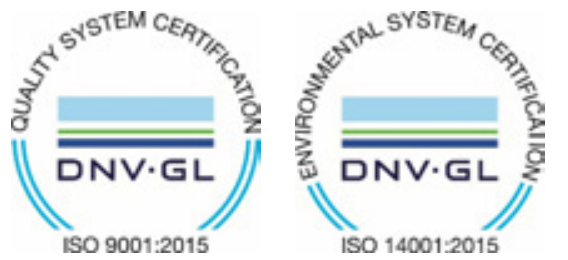

In 2003 Wageningen Environmental Research implemented the ISO 9001 certified quality management system.

Since 2006 Wageningen Environmental Research has been working with the ISO 14001 certified environmental care system.

By implementing the ISO 26000 guideline, Wageningen Environmental Research can manage and deliver its social responsibility.

Wageningen Environmental Research report 2980 | ISSN 1566-7197

Photo cover: Shutterstock 


\section{Contents}

$\begin{array}{ll}\text { Verification } & 5\end{array}$

$\begin{array}{ll}\text { Preface } & 7\end{array}$

$1 \quad$ General introduction 9

1.1 Objectives of the proposed document 9

1.2 Legal basis for the evaluation of pest control products in Kenya 9

1.3 Quality of data 9

2 Overall framework for the evaluation of pest control products in Kenya 10

$3 \quad$ Fast track procedure for low risk pest control products 11

3.1 Justification 11

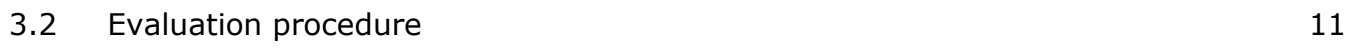

$\begin{array}{ll}\text { 3.3 Applicability of the fast track procedure } & 12\end{array}$

$4 \quad$ Evaluation of microbial pest control agents (MPCAs) 13

4.1 Introduction 13

4.2 Proposed framework for the evaluation of MPCAs in Kenya 13

$5 \quad$ Evaluation of chemical pest control agents - human health risk assessment 16

$\begin{array}{lll}5.1 & \text { Introduction } & 16\end{array}$

$\begin{array}{lll}5.2 & \text { Framework for human health risk assessment } & 16\end{array}$

$\begin{array}{ll}\text { 5.3 Hazard assessment - Adoption of toxicological reference values } & 17\end{array}$

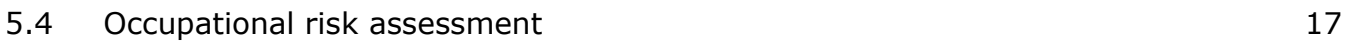

$\begin{array}{ll}\text { 5.4.1 Operator risk assessment } & 17\end{array}$

5.4.2 Worker risk assessment 18

5.4.3 Resident risk assessment 19

5.5 Consumer risk assessment 19

5.5.1 Introduction 19

5.5.2 Chronic dietary risk assessment 20

5.5.3 Acute dietary risk assessment 20

Evaluation of chemical pest control agents - environmental risk assessment 21

$\begin{array}{lll}6.1 & \text { Introduction } & 21\end{array}$

6.2 Framework for pollinator risk assessment 21

6.3 Framework the risk assessment for aquatic organisms 22

6.3.1 Principles of the risk assessment for aquatic organisms 22

6.3.2 Effect assessment 24

$\begin{array}{ll}\text { 6.3.3 Exposure assessment } & 25\end{array}$

$\begin{array}{lll}7 & \text { Registration by equivalence } & \mathbf{3 0}\end{array}$

$\begin{array}{lll}7.1 & \text { Introduction } & 30\end{array}$

7.2 Equivalence evaluation of chemical pesticides 30

$\begin{array}{ll}7.3 & \text { Equivalence evaluation of microbial pest control agents } 30\end{array}$

References

Annex 1 Correlation table between crops in the EFSA AOEM model and key Kenyan crops

Annex 2 Some details for risk assessment for aquatic organisms in the EU 34 



\section{Verification}

Report: 2980

Project number: 5200042849

Wageningen Environmental Research (WENR) values the quality of our end products greatly. A review of the reports on scientific quality by a reviewer is a standard part of our quality policy.

This report is a product of and has been approved by Kenyan-Dutch project group on strengthening the registration of pest control products in Kenya.

Approved team leader responsible for the contents,

name: M. de Potter

date: 17 December 2019 


\section{Preface}

The present document describes suggestions for further steps that can be taken with regard to the evaluation of pest control products in Kenya. The document should be read together with the document describing proposed guidance on dossier evaluation for the registration of pest control products in Kenya. That document provides guidance on dossier evaluation for the registration of pest control products in Kenya.

Both reports are the result of intensive collaboration between the PCPB and Dutch partners in the Pesticide management initiative East African Region: Kenya (PEAR-Kenya), work package B. The PEAR-Kenya project aims to contribute to sustainable agricultural production in Kenya through improving plant health, risk assessment, Integrated Pest Management (IPM), food safety and reducing the risks of pesticide use. The PEAR-Kenya project's specific aims are to stimulate Integrated Pest Management (IPM) and to improve the structure, clarity and the procedures of pest control product registration such that key products for Integrated Pest Management will be registered and become available on the market, without lowering (environmental) quality standards.

In work package $\mathrm{B}$ of the project joint efforts have been made to strengthen the administrative process and to review and further develop risk assessment procedures, both for low risk and for nonlow risk pest control products. The work resulted in the guidance for evaluation of pest control products described in the guidance document on evaluation for the registration of pest control products and the present implementation report which contains stepping stones for further development, and as such both contribute to a future complete pesticide evaluation manual for Kenya.

The project has been executed in collaboration with the Kenyan Pest Control Product Board (PCPB) and other stakeholders active in the field of plant protection and IPM, e.g. Ministry of Agriculture, Livestock and Fisheries, biological producers, chemical producers, farmers organisations, the International Centre of Insect Physiology and Ecology (ICIPE) and Jomo Kenyatta University of Agriculture and Technology (JKUAT). Also the Dutch authorities: the Dutch Board for the Authorisation of Plant Protection Products and Biocides (Ctgb) and The Netherlands food and consumer product safety authority (NVWA) were part of the project.

We thank the Dutch Ministry of Agriculture, Nature and Food Quality as well as the Embassy of the Netherlands in Nairobi for sponsoring and supporting this activity as part of the PEAR-Kenya project.

Louise Wipfler

Project manager PEAR-Kenya project 


\section{$1 \quad$ General introduction}

\subsection{Objectives of the proposed document}

Ter Horst et al. (2019) provides a proposal for guidance on dossier evaluation for the registration of pest control products in Kenya. This guidance document might serve as a starting point for further development of an evaluation manual for registration of pest control products in Kenya by the PCPB.

Ter Horst et al. (2019) provides guidance on a number of evaluations that need to be conducted when a pest control product is submitted for (re-)registration. These include low risk products, microbial pest control agents, human health risk assessment and pollinator risk assessment. The guidance presented in Ter Horst et al. (2019) is the most robust that is presently possible, given the data requirements in Kenya and the available local information relevant for the assessment methods.

However, during the various workshops that were organized to develop the guidance, recommendations have also been made on how to further refine the (risk) assessment methods and make them more specific to the Kenyan situation. In one case, the surface water risk assessment, no method was proposed yet as certain background studies need to be conducted first.

The present document provides reflections on what is needed to implement and further refine the guidance proposed in Ter Horst et al. (2019).

\subsection{Legal basis for the evaluation of pest control products in Kenya}

Currently, the legal basis for pesticide registration in Kenya is the Pest Control Products Act ${ }^{1}$. However, a new Pest Control Products Bill, 2019 has been drafted and is in the process of government review and approval.

It will be important to ensure that any legislation and the evaluation guidance are mutually harmonized, in particular with regard to protection goals and acceptability criteria for registration of pest control products in Kenya.

\subsection{Quality of data}

The data provided by the applicant should be of high quality and reliability: the studies should be conducted according to internationally accepted test guidelines, and with an acceptable code (e.g. OECD) of Good Laboratory Practice (GLP). Ter Horst et al. (2019) provides guidance on data quality.

\footnotetext{
1 Pest Control Products Act. Chapter 346. Revised edition 2012 [1985].
} 


\section{Overall framework for the evaluation of pest control products in Kenya}

The proposed overall framework for the evaluation of pest control products in Kenya is described in Ter Horst et al. (2019).

The overall framework for the evaluation of pest control products in Kenya starts with the equivalence assessment. However in practice, this first step in the framework is preceded by the registration application and submission of the full dossier.

\section{Completeness check}

First a completeness check is done. Considering the completeness check the PCPB might consider the following suggestions:

PCPB could consider further standardizing the completeness review, by elaborating an internal check-list which incorporates the EAC data conditionalities.

The East African Community (EAC) has adopted regionally harmonizing data requirements, which provide more guidance about the conditions under which specific data should be provided. The EAC guidelines can be used by PCPB to clarify for both applicants and regulators which data are needed under what circumstances.

Dossier evaluation - general

The risk assessments proposed in the project will increase the volume of work for the PCPB and therefore the PCPB will certainly require extra staff.

Dossier evaluation - order of steps in the process

Currently, after the completeness check, the technical dossier is evaluated by the PCPB before efficacy testing is done. This contains a proposed GAP.

In case the GAP is changed on the basis of local efficacy trails it is important that any risk assessments are updated by the applicant.

\section{Efficacy testing and efficacy evaluation}

The new EAC Efficacy testing guidelines should provide better guidance for trials. However, more crop/pest specific trial protocols will need to be elaborated, preferably regionally harmonized through EAC. 


\section{Fast track procedure for low risk pest control products}

\subsection{Justification}

The use of low risk pesticides (especially low risk biopesticides) is a key component for pest control in an Integrated Pest Management approach. To stimulate IPM a fast track procedure for identifying and evaluating low risk pest control products was developed with the objective to speed up the authorisation process for these products.

The procedure makes optimal use of the identification of low risk pesticides by reputable pesticide registration authorities, such as the European Union (EU) and the US Environmental Protection Agency (US-EPA). Furthermore, procedures for evaluation by analogy developed by FAO are used as a basis for the fast track procedure.

\subsection{Evaluation procedure}

The proposed evaluation procedure for low risk pest control products is described in Ter Horst et al. (2019).

The procedure follows the three main steps:

1. Identification of low risk active ingredient or MPCA

2. Assessment of similarity with the reference low risk active ingredient or MPCA

3. Evaluation of analogy with the low risk reference pest control product

\section{I dentification of low risk active ingredients/ agents}

Active substances/agents are considered to be low risk, if they are classified as potential or authorized low risk by the EU or as 'minimum risk pesticides' by the US-EPA.

Regulation (EU) 2017/1432 states: "semiochemicals are substances emitted by plants, animals and other organisms which are used for intra-and inter-species communication, have a target-specific and non-toxic mode of action and are naturally occurring. They are generally effective at very low rates, often comparable to levels that occur naturally. In light of current scientific and technical knowledge it is also appropriate to provide that semiochemicals should be considered as low-risk substances".

PCPB might consider establishing a national list of low risk pesticides based on broader lists of criteria presently applied (e.g. semiochemicals, baculoviruses, criteria of other reputable regulators).

\section{Assessment of similarity}

No specific guidance is developed in the EU or USA to assess whether the active substance/agent of the local product is sufficiently similar to the active substance/agent classified as low-risk or potentially low-risk by the EU or as minimum risk pesticides by the US-EPA.

The PCPB could consider to develop a specific procedure/protocol for assessing whether the active substance/agent of the local product is sufficiently similar to the active substance/agent classified as lowrisk or potentially low-risk by other reputable regulator. 


\section{Evaluation by analogy}

Evaluation by analogy applies bridging methods for the evaluation of efficacy and risk of the pesticide and is less complex, uses fewer data and requires less human resources than a complete evaluation. However, evaluation by analogy is also less precise and may leave considerable uncertainties about efficacy and risk under the local conditions of use (FAO, 2019). Because low risk products pest control products are not expected to cause important human health and environmental risks, the inherent uncertainty of registration by analogy is therefore not so important. There is therefore no impediment for implementing the guidance given on evaluation by analogy in Ter Horst et al. (2019).

\subsection{Applicability of the fast track procedure}

The fast track procedure may not be applicable for many microbial pest control agents as one of the criteria is that the strain is identical. This an argument for further developing the procedure for the evaluation of microbial pest control agents. 


\section{$4 \quad$ Evaluation of microbial pest control agents (MPCAs)}

\subsection{Introduction}

It is expected that many microbial pest control products do not pass the fast track procedure for lowrisk products. The low risk status of a local product is based on whether the active substance/agent of the local product is sufficiently similar to the active substance/agent classified as low-risk or potentially low-risk by the EU or as minimum risk pesticides by the US-EPA. As one of the criteria for MPCAs in this procedure is, that the strain should be identical, it is expected that many microbial pest control products do not pass the low-risk fast track procedure. An adequate evaluation procedure for MPCAs is therefore essential.

Like in the EU, approval of microbial active agents is done on strain/isolate level. The exception to this is the group of Baculoviruses which, like in the EU, can be approved at species level. It is proposed that the PCPB uses the EU guidance on how new isolates of Baculovirus species can be evaluated (SANCO/0253/2008_rev.2; see list of references for link to website).

\subsection{Proposed framework for the evaluation of MPCAs in Kenya}

The proposed framework for the evaluation of microbial pest control products is described in Ter Horst et al. (2019).

\section{I dentity}

For Kenya identification and quantification of a microbial agent and possible impurities, additives and/or contaminants ${ }^{2}$ should be provided in the dossier. The applicant should also submit the method to determine the identity of the MPCA as part of the active substance dossier.

PCPB may cross-check the identification and quantification of a microbial agent and possible impurities, additives and/or contaminants by a local or international laboratory.

It is advised that the Kenyan government stimulates the establishment of a local accredited laboratory, qualified to identify and quantify a MPCA and possible impurities, additives and/or contaminants.

\section{Relation to human pathogens and infectiveness}

It is advised that the PCPB develops a specific protocol for literature research on human pathology and infectiveness. The protocol should amongst others contain criteria for including or excluding data found in literature. The US-EPA Microbial Risk Assessment Guideline provides useful information on this issue (USEPA, 2012).

The applicant should provide information on the infectiveness of the microorganism, including information on the growth of the specific strain at different temperatures in the dossier.

\footnotetext{
2 A contaminant is defined as an unintentional microbial ingredient that occurs during manufacturing.
} 
The applicant should provide information on the microorganism's resistance or sensitivity to antibiotics or other antimicrobial agents. Information on the stability, in terms of genetic transfer, is of particular interest if these genes are carried on mobile genetic elements, since this may be of medical relevance.

Expert judgement is needed to decide, based upon the information provided (incl. results of tier 1 tests), on whether the MPCA is likely to be pathogenic or infective. It might be considered to develop a decision supporting procedure for assessing the tier 1 tests.

\section{I dentify metabolites of potential concern}

Currently, to our best knowledge, no ready-to-use guidance exists for the identification and assessment of metabolites of potential concern. A working document (including extensive appendix) has been written by the OECD (2018), which provides background information and suggestions on the assessment of hazards and risks of microbial metabolites but does not have the status of a guidance document. In the EU, a guidance document for the assessment of metabolites is currently being prepared. The aim is to complete this guidance in 2020. An important starting point for this EU guidance is that it is not required to perform an assessment of all microbial metabolites produced by a microorganism as performed for chemical active substances; this is neither feasible nor necessary from a risk perspective. The aim of the EU guidance will be to collect sufficient data to be able to use expert judgment to determine which metabolites are of concern and provide guidance on how these metabolites should be further addressed in the risk assessment.

The following may be considered by the PCPB. For MPCA's that have been on the market for several years and for which no adverse effects have been demonstrated for humans and the environment, the in situ formation of metabolites of potential concern is of no concern as they are unlikely to be produced at relevant concentrations.

Currently since there is no EU harmonization on the issue of metabolites of potential concern further information is generally requested at EU level. Scheepmaker et al. (2019) provides an interesting perspective to this issue, in a review paper with the title: 'Sense and nonsense of the secondary metabolites data requirements in the EU for beneficial microbial control agents'.

There will be many features that are not studied and described. Try to work with the information that is available and only work on those metabolites in the risk assessment for which there is an indication for a concern (i.e., foreseeable risks).

Following from this line of reasoning, when the active agent in a microbial pest control product is in fact a metabolite, this metabolite is considered to confer a foreseeable risk and should be addressed in the risk assessment (i.e. products which include genera which form actives in the MPCA-based product e.g. Bacillus, Pseudomonas and Beauveria).

\section{Qualitative and quantitative risk assessment for metabolites of potential concern}

A. Consumer (dietary) risk assessment for metabolites of potential concern of MPCAs The consumer (dietary) risk assessment for microorganism is generally qualitative i.e. if toxicity, infectivity and pathogenicity was not observed than no risk assessment for the microorganism is needed.

A qualitative risk assessment can be done for metabolites produced by the microorganism once located on the crop (in situ production of metabolites). Quantifying the exposure of in situ produced 
metabolites is very difficult as this is influenced by a set of temporal and spatial variable environmental factors such as climate, microbiome, crop type etc. However, based on the information available an attempt could be done to build an argumentation for negligible exposure.

The PCPB could consider, just like the US-EPA, to skip such a qualitative consumer risk assessment if there are no indications in literature that the micro-organism by nature does not produce significant amounts of a metabolite which is harmful to humans (rationale if the micro-organism by nature does not produce significant amounts of a metabolite which is harmful to humans than it is not expected that they will start producing significant amounts of the same metabolite after applying it as a pest control product).

For the quantitative dietary risk assessment of metabolites of potential concern present in the microbial product a tiered approach is applicable. The first tier is a simple quantitative dietary risk assessment that is described in Ter Horst et al. (2019). This simple method involves the comparison of exposure levels to specific reference values or the Threshold of Toxic Concern (TCC) value.

The second tier is the procedure for the dietary risk assessment as used for the evaluation of chemical pesticides (Ter Horst et al., 2019). However, the Dutch Board for the Authorisation of Plant Protection Products and Biocides (Ctgb) has the experience that for the microbial agents they evaluated so far, the first tier of the quantitative dietary risk assessment of metabolites of potential concern never resulted in unacceptable risks i.e. they never had to use the second tier for any of the microbial agents for which authorization was requested in the Netherlands.

B. Occupational risk assessment for metabolites of potential concern of MPCAs

The occupational risk assessment for microorganism is generally qualitative i.e. if toxicity, infectivity and pathogenicity was not observed than no risk assessment for the microorganism is needed.

A qualitative risk assessment can be done for in situ produces metabolites. However, like explained in the section on the consumer risk assessment it might be considered to omit this step.

The PCPB could consider, just like the US-EPA, to skip a qualitative occupational risk assessment if there are no indications in literature that the micro-organism by nature does not produce significant amounts of a metabolite which is harmful to humans.

C. Environmental hazard assessment for metabolites of potential concern of MPCAs

If toxicity, infectivity and pathogenicity was not observed than no environmental risk assessment for the microorganism itself is needed, however metabolites of potential concern need to be assessed. At this point it is recommended to just assess the hazards because it is inappropriate to evaluate the environmental risk of potentially very low risk products like microbial agents and their by-products in a more elaborated way than recommended for the conventional chemical pesticide products. Hazard identification according the US-EPA test guidelines ${ }^{3}$ will therefore be used as a first tier for the assessment of metabolites of potential concern of a MPCA.

The US-EPA test guidelines require that a maximum hazard dose is tested, which is based on a safety factor times the maximum predicted environmental exposure. When the test shows no effect on the tested non-target organisms and plants then this is considered as sufficient prove that the MPCA poses no unacceptable risks to the environment.

\footnotetext{
3 https://www.epa.gov/test-guidelines-pesticides-and-toxic-substances/series-885-microbial-pesticide-test-guidelines (Website last entered 8 November 2019).
} 


\section{$5 \quad$ Evaluation of chemical pest control agents - human health risk assessment}

\subsection{Introduction}

Ter Horst et al. (2019) provides guidance on the assessment of the risk of active ingredients/agents in pest control products on human health (occupational and consumer).

This chapter provides advice on follow up actions needed to implement the methods for performing human health risk assessment that are described in Ter Horst et al. (2019).

\subsection{Framework for human health risk assessment}

Conducting human health risk assessments according the guidance in Ter Horst et al. (2019) is very likely to be more strict than the present evaluation procedures.

As a result, the registration of more pest control products and/or more uses of such products will not be approved, than is presently the case.

To ensure a level playing field, ideally all registered pest control products and newly to be registered products should be evaluated using the same risk assessment procedure. However, the present human capacity at PCPB is not sufficient to conduct human health risk assessments of all these products within a limited time frame.

It is therefore suggested that initially, these risk assessments are conducted for the following groups of pest control products:

- All products with new active ingredients for Kenya;

- Major use products (i.e. most imported/used pesticide active ingredients and products, by volume and/or pesticide products used in the major crops, by surface area);

- Products classified as showing a high human health hazard (and therefore possibly also a high risk);

- Active ingredients and products that, under local conditions of use, have caused human health effects (e.g. based on poison centre statistics, epidemiological research or monitoring studies).

It is recommended that the PCPB reviews its list of registered pesticides against the above criteria and establishes a short-list of products that should be reviewed for human health risks.

It is important that human health risk assessments are not limited to new active ingredients for Kenya. Since many newer active ingredients tend to pose less risk than some of the older molecules, postponing risk assessments of older pesticides will de facto lead to higher risk products being favoured over lower risk ones. This would contradict PCPB's policy of moving towards more sustainable pest management.

It is recognized, however, that conducting risk assessments for the above priority groups of pest control products will require considerable time.

It is suggested that PCPB establishes a calendar of re-evaluations, which among others takes into account expiry dates of product registrations. 


\subsection{Hazard assessment - Adoption of toxicological reference values}

It is advised that the PCPB establishes a toxicological list of endpoints as outcome of each hazard assessment. The endpoint list should, in principle, be the same for each active ingredient (by manufacturing source/process) and product. This should ensure that the same endpoints are used for identical/equivalent active ingredients and products.

\section{$5.4 \quad$ Occupational risk assessment}

\subsubsection{Operator risk assessment}

\subsubsection{Exposure models applied in Kenya}

For field uses of pesticides, the EFSA AOEM model is the preferred model. For manual spray application in the field, the Croplife OPEX model would be better fitted. Therefore, the EFSA AOEM model is used as a first tier and the Croplife OPEX model as a second tier. For greenhouse uses of pesticides, the ECPA Southern Greenhouse Model is considered the preferred model.

\subsubsection{EFSA AOEM model}

It is proposed to use the EFSA AOEM model as a first tier of the risk assessment for operators.

Considering an adult operator, different default values are assumed in the model.

It is advised that the PCPB verifies whether the default values applied in the model are relevant for the situation in Kenya and inform applicants about the national defaults to be used.

If the model's default values are comparable or worst case to the Kenya situation, they can be used as such. If a parameter value in Kenya is likely to be more worst case than what is assumed in the model, a correction for this should be made (Table 1 ).

Table 1 Default parameters in the EFSA AOEM model of which should be checked whether they are relevant for the situation op operators in Kenya.

\begin{tabular}{lll} 
Parameter & Default in model & Applicable in Kenya? \\
Body weight & $60 \mathrm{~kg}$ & \\
\hline Exposure duration & 8 hours & \\
\hline Hectares treated per day & Manual handheld: 4 ha \\
& Manual knapsack: 1 ha \\
& Vehicle mounted: 10 or 50 ha \\
& depending on crop type & \\
\hline Crop types & List of 'European' crop types & $\begin{array}{l}\text { Table needs to be established correlating Kenyan crops to } \\
\text { the model crops, on the basis of crop structure which is }\end{array}$ \\
& & $\begin{array}{l}\text { (Table } 7 \text { in Annex 1) } \\
\text { major parameter for operator exposure (Annex 1) }\end{array}$
\end{tabular}

\subsubsection{The Croplife OPEX model}

The EFSA AOEM model is proposed as a first tier. However, if manual spray application results indicate an exceedance of the reference value (AOEL), then the Croplife OPEX model can be used as a refinement. 
The advantage of the Croplife OPEX model is that many parameters can be adjusted. Therefore, in the model, values more representative of the situation in Kenya can be taken into account.

It is advised that the PCPB verifies whether the default values applied in the model are relevant for the situation in Kenya and inform applicants about the national defaults to be used.

If the model's default values are comparable or worst case to the Kenya situation, they can be used as such. If a parameter value in Kenya is likely to be more worst case than what is assumed in the model, a correction for this should be made (Table 2).

Table 2 Default parameters in the CropLife OPEX model of which should be checked whether they are relevant for the situation in Kenya.

\begin{tabular}{ll} 
Parameter & Default in model \\
\hline Body weight & $60 \mathrm{~kg}$ \\
\hline Workwear & Normal workwear (long sleeved shirt and long \\
& trousers) assumed as default \\
& Additional PPE can be selected \\
\hline Work rate & Aerial: 500 ha/day \\
& Tractor downwards: 80 ha/day \\
& Tractor upwards: 15 ha/day \\
& Handheld: 1 ha/day
\end{tabular}

\subsubsection{The ECPA Southern Greenhouse Model}

For greenhouse uses of pesticides, the ECPA Southern Greenhouse Model is proposed. The advantage of this model is that all parameters can be adjusted and that different scenarios like downwards spraying and up- and sideways spraying can be evaluated. This is not the case for other models (for instance The Dutch Greenhouse model only evaluates up- and sideways spraying, which is a worst-case situation). Therefore, model parameters more representative of the situation in Kenya can be taken into account.

It is advised that the PCPB verifies whether the default values applied in the model are relevant for the situation in Kenya (Table 3 ) and inform applicants about the national defaults to be used.

Table 3 Default parameters in the ECPA Southern Greenhouse Model of which should be checked whether they are relevant for the situation in Kenya.

\begin{tabular}{ll} 
Parameter & Default in model \\
Body weight & $70 \mathrm{~kg}$ \\
\hline Workwear & Workwear or alternatively t-shirt and shorts \\
\hline Work rate & No defaults given. Determine values relevant for \\
& Kenya (depending on crop)
\end{tabular}

\subsubsection{Worker risk assessment}

It is proposed to use the EFSA AOEM model for the risk assessment for workers.

It is advised that the PCPB verifies whether the default values applied in the model are relevant for the situation in Kenya (Table 4) and inform applicants about the national defaults to be used. 
If the model's default values are comparable or worst case to the Kenya situation, they can be used as such. If a parameter value in Kenya is likely to be more worst case than what is assumed in the model, a correction for this should be made.

Table 4 Default parameters in the EFSA AOEM model of which should be checked whether they are relevant for the situation of workers in Kenya.

\begin{tabular}{lll} 
Parameter & Default in model & Applicable Kenya? \\
Body weight & $60 \mathrm{~kg}$ & Table needs to be established correlating \\
\hline $\begin{array}{l}\text { Worker activities for each } \\
\text { crop type }\end{array}$ & See Table 8 & Kenyan crops to the model crops, on the \\
\hline $\begin{array}{l}\text { Duration of worker } \\
\text { activities for each crop }\end{array}$ & See Table 8 & basis of crop structure which is major \\
type & & parameter for operator exposure (see \\
\hline
\end{tabular}

The DFR (Dislodgeable Foliar Residue) and DT50 defaults seem to be acceptable for Kenya. These default values are based on a large database covering studies performed on different crops, in both the EU and USA. It is proposed to use these defaults also in Kenya. These values may be further refined based on actual study data on the relevant crop using the critical GAP for that active ingredient.

It is advised that the PCPB verifies whether the default values for the (Dislodgeable Foliar Residue) and DT $_{50}$ defaults are acceptable for Kenya and inform applicants about the national defaults to be used.

\subsubsection{Resident risk assessment}

For the risk assessment of residents (both children and adults) the EFSA AOEM model is proposed. Most of the parameters used in the model cannot be adjusted and are based on data from the US EPA or Europe.

It is advised that the PCPB verifies whether the default value used for the body weight of a child $(10 \mathrm{~kg})$ is relevant for the situation in Kenya and inform applicants about the national defaults to be used.

\subsection{Consumer risk assessment}

\subsubsection{Introduction}

For the chronic consumer risk assessment the FAO IEDI (international estimated dietary intake) model was proposed. For the acute consumer risk assessment, the FAO IESTI (international estimated shortterm intake) model was proposed. 


\subsubsection{Chronic dietary risk assessment}

It is advised that the PCPB discusses the following issues and takes decisions on them.

- Which residue definition to use? For instance the EU (EFSA) and the WHO (JMPR) can have different residue definitions.

- What MRL to use? Codex MRLs or European MRLs can be different.

- Is a tiered approach agreeable? Starting risk assessment with MRL as worst case, and in case the ADI is exceeded, a possible refinement based on residue trials (STMR data).

- Is a diet agreed upon? A cluster diet for East-Africa is included in the FAO IEDI model. It should be checked if the dietary information seems applicable to Kenya or if certain food items have to be added or adjusted for their intake.

\subsubsection{Acute dietary risk assessment}

It is advised that the PCPB discusses the following issues and takes decisions on them.

- Which residue definition to use? For instance the EU (EFSA) and the WHO (JMPR) can have different residue definitions.

- What MRL to use? Codex MRLs or European MRLs can be different.

- Is a tiered approach agreeable? Starting risk assessment with MRL as worst case, and in case the ARfD is exceeded, a possible refinement based on residue trials (STMR and HR data).

- Is a diet agreed upon? The model does not contain specific data for Kenya. Do adjustments have to be made to include specific food items eaten in Kenya? Or is the diet as included in the model representative for Kenya? Is it necessary to obtain more information on diets in Kenya? 


\section{Evaluation of chemical pest control agents - environmental risk assessment}

\subsection{Introduction}

The PCPB identified the protection of pollinators and aquatic organisms as priority. The framework developed for the risk assessment of pollinators is described in (Ter Horst et al., 2019). This chapter provides advice on follow up actions needed to implement the methods for performing pollinator risk assessments that are described in Ter Horst et al. (2019).

The framework for the risk assessment of aquatic organisms has not been developed and is therefore not part of Ter Horst et al. (2019). A first step towards guidance has been made however, which is described in section 6.3.

\subsection{Framework for pollinator risk assessment}

To be able to implement the methods for pollinator risk assessment as described in Ter Horst et al. (2019), it is advised that the PCPB follows up on the two aspects below:

- Elaborate a table on the attractiveness of crops to bees, for the major crops on which pesticides are used in Kenya.

- Identify key bee species that are important for crop pollination in Kenya, or are otherwise important (e.g. for biodiversity), and compile biological and ecological data that will help describe exposure of these species to pesticides.

Conducting risk assessments for pollinators according the guidance in Ter Horst et al. (2019) is very likely to be more strict than the present evaluation procedures. As a result, the registration of more pest control products and/or more uses of such products will not be approved, than is presently the case.

To ensure a level playing field, ideally all registered pest control products and newly to be registered products should be evaluated using the same risk assessment procedure. However, the present human capacity at PCPB is not sufficient to conduct risk assessments for pollinators of all these products within a limited time frame.

It is therefore suggested that initially, these risk assessments are conducted for the following groups of pest control products:

- Major use products (i.e. most imported/used pesticide active ingredients and products, by volume and/or e products used in the major crops, by surface area);

- Products classified as showing a high hazard for pollinators (and therefore possibly also a high risk);

- Active ingredients and products that, under local conditions of use, have caused environmental effects (e.g. based on monitoring studies);

- All products with new active ingredients for Kenya.

It is recommended that PCPB reviews its list of registered pest control products against the above criteria and establishes a short-list of products that should be reviewed for pollinator risks. 
Since many newer a.i.'s tend to pose less risk than some of the older molecules, postponing risk assessments of older pesticides will de facto lead to higher risk products being favoured over lower risk ones. This would contradict PCPB's policy of moving towards more sustainable pest management.

It is recognized, however, that conducting risk assessments for the above priority groups of pest control products will require considerable time.

It is therefore that PCPB establishes a calendar of re-evaluations, which among others takes into account expiry dates of product registrations.

The outcome of the pollinator risk assessment for Kenya is that the pesticide is estimated to be low, moderate or high risk to bees, either in the crop and/or off-crop, when used as recommended on a specific crop. The possible combinations of outcomes are listed in Table 11 in Ter Horst et al. (2019), with for each of the combinations risk management considerations are suggested.

Note that the risk management considerations in Table 11 in Ter Horst et al. (2019) are proposals. The PCPB and/or responsible risk managers take the final risk management decision which may not necessarily be based on solely the outcome of the pollinator risk assessment.

\subsection{Framework the risk assessment for aquatic organisms}

\subsubsection{Principles of the risk assessment for aquatic organisms}

\subsubsection{Protection goals}

Protection goals described in legal frameworks are often too broad to be directly applicable for risk assessment and regulatory decision-making. For example, the European legislation states that that Plant Protection Products 'shall have no unacceptable effects on the environment'. Kenyan legislation states that 'The Board may refuse to register a pest control product if in its opinion the use of the pest control product would lead to an unacceptable risk or harm to public health, plants, animals or the environment.

To be operational, it is important that these general and broadly formulated protection goals are specified such that they constitute an explicit expression of the environmental components that need protection, the maximum impacts that is predicted or can be tolerated, where and over what time period. These specified protection goals form the basis for the assessment of the probability and seriousness of harmful effects (EFSA, 2016).

In general terms the protection goal for aquatic organisms in the water column is defined in the $\mathrm{EU}$ as follows: 'protect aquatic organisms living in the water column and the sediment of permanent edge- offield surface waters'.

In addition, the following three questions must be answered to come to a specific and quantified risk assessment:

1. Which are the key driver groups of aquatic organisms that should be protected

2. Where in Kenya (i.e. what type of water bodies, where located) should these be protected?

3. How much adverse impact is acceptable, and over which time period?

Ad. 1.

EFSA (EFSA, 2013) identified seven key driver groups, being aquatic algae, aquatic vascular plants, aquatic invertebrates, aquatic vertebrates and aquatic microbes. The data requirements related to these key driver groups are given below:

- Aquatic algae: Green algae, e.g. Pseudokirchneriella subcapitata.

- Aquatic vascular plants: Lemna gibba/minor, Glyceria maxima, Myriophyllum. 
- Aquatic invertebrates:

- Crustaceans: Daphnia magna/pulex, Americamysis bahia.

- Insects: Chironomus riparius.

- Oligochaets: Lumbriculus spp.

- Aquatic vertebrates: Fish, e.g. Oncorhynchus mykiss.

For microbes no standard tests are available.

In how far these standard tests can be used for the risk assessment in Kenya needs to be assessed.

Ad 2.

The 'where' question can in principle in general terms be answered by ecologists/ecotoxicologists. EU EFSA (2013) defined this part as: 'permanent surface waters next to treated fields'. To enable the quantification of pesticide concentrations to which the organisms are exposed in Kenyan surface waters, data on surface waters in Kenya is needed as well as cropping information and other environmentally relevant data.

Ad 3.

The acceptance of adverse effects relates to the recovery of populations. Generally for fish no adverse effects are accepted at all whereas for plants some effect over a short period may be acceptable.

It is advised to start the risk assessment development for aquatic ecosystems with an adequate definition for the protection goal as basis for the future risk assessment of aquatic organisms in Kenya. This definition must be underpinned with agro- environmental data specifically for Kenya. Experts in the field of Kenyan aquatic systems (hydrologists and aquatic ecologists) as well as agronomists should be part of the definition process.

\subsubsection{Risk characterisation}

\section{Toxicity-Exposure Ratio approach}

The risk for aquatic organisms is characterised by comparing the concentration at which effects are detected with the exposure concentration in surface water caused by the intended use of the pesticide product. If the exposure concentration exceeds the concentration at which unacceptable effects are detected, the risk of the use of the pesticide is considered unacceptable.

In the EU the so-called Toxicity-Exposure Ratio (TER) is used the characterise the risk. The TER is defined as follows:

$T E R=\frac{\text { Toxicity endpoint } / /_{A F}}{P E C}$

Where PEC is the Predicted Environmental Concentration and AF is the Assessment factor (i.e. often also called a safety factor), these factors vary between 10 and 100 . In the EU the threshold value for acceptable risk is 1 ; i.e. a TER of 1 or larger indicates acceptable risks.

In an international context (incl. US-EPA) the Exposure-Toxicity Ratio (ETR) Risk Quotient (RQ) is used. This approach is more intuitive than the TER approach because a high value of the ETR or RQ is associated with high risks.

For developing risk assessment methods for Kenya, it is advised that a choice is made between either using the TER approach or the ETR approach. 
The toxicity endpoint is the result of the effect assessment, which is elaborated below. The PEC is the result of the exposure assessment which is discussed in section 6.3.3.

\subsubsection{Effect assessment}

The result of an effect assessment is the toxicity endpoint.

\section{Tiered approach in the effect assessment}

Corner stone of the EU effect assessment methodology is the tiered approach (Figure 1).

For developing risk assessment methods for Kenya, it is advised to decide whether a tiered approach is desirable for Kenya.

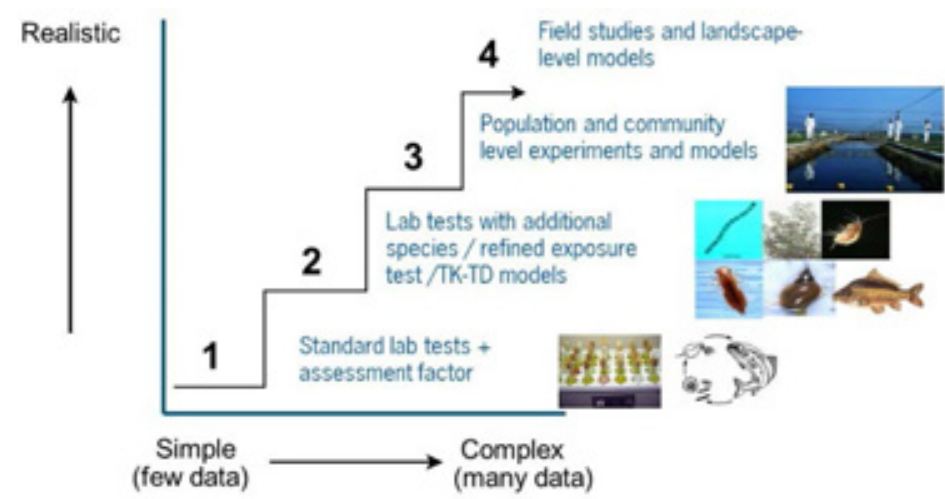

Figure 1 Tiered approach in the EU effect assessment methodology for aquatic organisms.

\section{Tier-1}

For Tier 1 toxicity tests (organisms, duration, endpoints) and derivation of the RACs the specifications as given in Table 5 (acute effect assessment) and Table 6 (chronic effect assessment) are used in the EU.

It could be considered to accept endpoint data from other countries/regions than Kenya/East African Community. Generally the EU Tier 1 endpoints will be protective for the Kenyan situation (Daam and van den Brink, 2010) ${ }^{4}$. Brock et al. (2016) concluded that the Tier 1 endpoints of neonicotinoids are not protective for micro/mesocosms. There are indications that micro/mesocosm studies performed with neonicotinoids in temperate regions are not protective for tropical regions (Sumon et al., 2018). Further reasoning result in the conclusion that EU Tier1 endpoints of neonicotinoids might not be protective for situations different from the EU (e.g. tropical situation).

It could be considered to evaluate whether specific local Kenyan (tropical) taxa, not represented by the current standard test species in use (in EU or countries/regions with reputable registration systems), are at risk. If this is the case, as a next step, it could be tested whether selected surrogate indigenous test species are representative for local Kenyan freshwater ecosystems. This can be done by conducting (tropical) model ecosystem studies covering a range of pesticide concentrations.

\footnotetext{
4 Except for the neonicotinoids, there are up till now no consistent differences in sensitivity between temperate and tropical ecosystems found, but indirect effects and recovery patterns will differ.
} 
Table 5 Deriving RACs for the acute effect assessment - Tier 1

\begin{tabular}{llll} 
Organism & Duration & Endpoint & RAC \\
Arthropods - Daphnia spp. (magna) & $48 \mathrm{~h}$ & $\mathrm{EC}_{50}$ & $\mathrm{EC}_{50} / 100$ \\
\hline Additional arthropod - Chironomus & $48 \mathrm{~h}$ & $\mathrm{EC}_{50}$ & $\mathrm{EC}_{50} / 100$ \\
\hline Additional arthropod - Americamysis & $48 \mathrm{~h}$ & $\mathrm{EC}_{50}$ & $\mathrm{EC}_{50} / 100$ \\
\hline Fish - Oncorhynchus mykiss & $96 \mathrm{~h}$ & $\mathrm{LC}_{50}$ & $\mathrm{EC}_{50} / 100$ \\
\hline
\end{tabular}

Table 6 Deriving RACs for the chronic effect assessment - Tier 1

\begin{tabular}{|c|c|c|c|}
\hline Organism & Duration & Endpoint & RAC \\
\hline Arthropods - Daphnia spp. & $21 \mathrm{~d}$ & $\mathrm{EC}_{10}$ or NOEC & $\mathrm{EC}_{10} / 10$ \\
\hline Additional arthropod - Chironomus & $20-28 d$ & $\mathrm{EC}_{10}$ or NOEC & $\mathrm{EC}_{10} / 10$ \\
\hline Fish - ELS & var. & $\mathrm{EC}_{10}$ or NOEC & $\mathrm{EC}_{10} / 10$ \\
\hline Fish - FFLC & var. & $\mathrm{EC}_{10}$ or NOEC & $\mathrm{EC}_{10} / 10$ \\
\hline Algae - diatom & $72 \mathrm{~h}$ & $\mathrm{E}_{\mathrm{r}} \mathrm{C}_{50}$ & $\mathrm{E}_{\mathrm{r}} \mathrm{C}_{50} / 10$ \\
\hline Macrophyte - Lemna, others & $7-14 d$ & $\mathrm{E}_{\mathrm{r}} \mathrm{C}_{50}$ & $\mathrm{E}_{\mathrm{r}} \mathrm{C}_{50} / 10$ \\
\hline
\end{tabular}

Note that the $\mathrm{EC}_{10}$ is preferred over the NOEC

It is proposed that testing is done with the active ingredient by preference; however the testing of formulated products can be required where: $\mathrm{i}$ ) the acute toxicity of the preparation cannot be predicted on the basis of the data for the active substance or ii) the intended use can result in direct exposure to water or iii) the extrapolation on the basis of available data for a similar preparation is not possible.

Some more background information on the higher effect tiers as used in the EU is provided in Annex 2.

For developing guidance for the effect assessment for the aquatic ecosystem in Kenya, it is advised to decide on:

- Which effects (i.e. which organisms) should be tested for both the acute and chronic assessment

- Duration of the test

- Endpoint of the test

- Value of the safety factor

\subsubsection{Exposure assessment}

The result of the exposure assessment is the PEC (Predicted Environmental Concentration) to be used for the risk characterisation (Eq. 1).

The EU approach for the exposure assessment is modelling (i.e. calculating the PECs using a simulation model). Transport to and behaviour of pesticides in surface water is simulated using simulation models and standard scenarios specifying agro-environmental conditions. These standard scenarios ensure consistent and reproducible calculations because the influence of the person that calculates the PEC is minimized. Moreover, standard scenarios make the use of complex simulation models much easier for regulators because a large part of the model input is fixed.

An exposure scenario can be defined as a unique combination of agronomic and environmental conditions (such as climate, hydrogeology, surface water characteristics, soil and topography), that realistically represents significant areas within which conditions are relatively homogeneous with respect to modelling input parameters (FOCUS, 1996). Exposure scenarios characterise the exposure 
in the environment which is compared to ecotoxicological effect concentrations to predict risks for the considered organisms.

To estimate local exposure (i.e. the PEC) adequately, it is needed to develop local exposure scenarios that protect e.g. $90 \%$ (exact percentage is a policy decision) of all situations in the country or the region (examples are EU: FOCUS, 2001, China: Ter Horst et al., 2014, Ethiopia: Adriaanse et al., 2015). These scenarios need to be parameterized in suitable simulation models.

Developing location specific exposure scenarios is time consuming and costly and preferably involves high resolution spatial and temporal data. This task was not feasible in the PEAR Kenya project.

It is advised to conduct the task of developing local exposure scenarios in a regional contact (e.g. the East African Community).

Ter Horst et al. (2014) and Adriaanse et al. (2015) provide a structured and simplified procedure that was designed to develop exposure scenarios within projects with a limited time span. They applied this procedure in respectively China and Ethiopia. The procedure employs ten steps. The three main steps in the development of exposure scenarios compromise:

1. Definition of the protection goals and specification of the scenario zones in which the protection goal does or does not exist;

2. Design and application of the scenario selection procedure and

3. Parameterization of the scenarios, in order to be able to perform simulations for combinations of pesticides, application pattern and possibly crops.

Large parts of the following text are taken from Adriaanse et al. (2015).

The stepped procedure seems linear, but in reality retracing to earlier steps is sometimes necessary.

The first step consists of making an inventory of agro-environmental conditions and pesticide use data for the target country/region relevant for the protection of the aquatic ecosystem, such as climate, soils, land use, crops and agricultural practices, surface water systems, size of catchment and the pesticide use and application techniques. If possible and relevant geographically distributed data, e.g. for climate and soils is gathered.

The second step consists of identifying the number and extent of the scenario zones. Should one scenario cover the entire country or should the country be divided into several zones to account for its diverse agro-environmental conditions? The choice for scenario zones has consequences for the registration system, so, next to scientists, risk managers should be involved. If there is only a single scenario and the compound fails to pass it, there will be no registration. If there are multiple scenarios, the compound may fail some scenarios and pass some others and this means that in some zones registration would be possible, while in others not, or only with restrictions. Therefore, using multiple scenario zones, some flexibility is introduced in the registration procedure. It is important to decide upon the number of scenario zones in an early stage of the project, because this determines the definition of the scenarios: if there is one zone there is only one scenario that represents e.g. the 90th percentile worst case situation of the entire country. When using several zones, the scenario should represent the 90th percentile worst case situation for each scenario zone separately. Different types of criteria may exist for dividing the country, e.g. using agro-ecological zones.

In the third step options for protection goals are defined, such as drinking water produced from groundwater, drinking water produced from surface water, the aquatic ecosystem, birds and mammals, pollinators etc. Three questions should be asked: i) what should be protected, ii) where to protect and iii) how strict? In this step the emphasis is upon the spatial component, the 'what' and 'where' questions. It is the role of scientists to draw the list of protection goals options. 
In the fourth step policy makers select protection goals from the list with options. Next, it is determined which protection goals are valid for each of the scenario zones. The scenario zones may be identified into further detail in this step by considering especially the overlap of areas where the protection goal is relevant and where agriculture uses pesticides. If the protection goals focus (indirectly) on human health, it may be an intelligent, pragmatic choice to consider especially areas where the most toxic compounds are used, e.g. insecticides, instead of herbicides. In this way, some crops may turn out to be more relevant than others. Policy makers may also set priorities in the operationalisation of the protection goals. The reason is that each protection goal needs its own assessment method. Considerations for setting priorities may include the balancing of economic versus environmental issues, or pragmatic reasons like considering only areas where pesticides are currently used, neglecting areas where pesticides may also be used in the future.

The fifth step consists of the definition of the conceptual model for the protection goals. A conceptual model consists of an explanatory picture or drawing plus a description of the protection goal. Relevant elements may be:

- Lay out of the protection goal, e.g. dimensions of surface water body, size of surrounding fields, fields treated, catchment size;

- Entry routes of pesticides;

- Farming practices and characteristics, such as e.g. land preparation, size of fields;

- Application techniques used (with links to crop management);

- Relevant crops (on which pesticides are used), e.g. crop calendar with main crop management activities and

- Relevant pesticide processes (focussing on exceptional or country-specific aspects).

The conceptual model should contain all relevant information for determining the exposure. If two fundamentally different situations exist for one protection goal, and it is a priori not evident which situation represents the 'realistic worst case' situation, then it may be necessary to design two conceptual models, e.g. surface water adjacent different types of land use like paddy rice or orchards. 


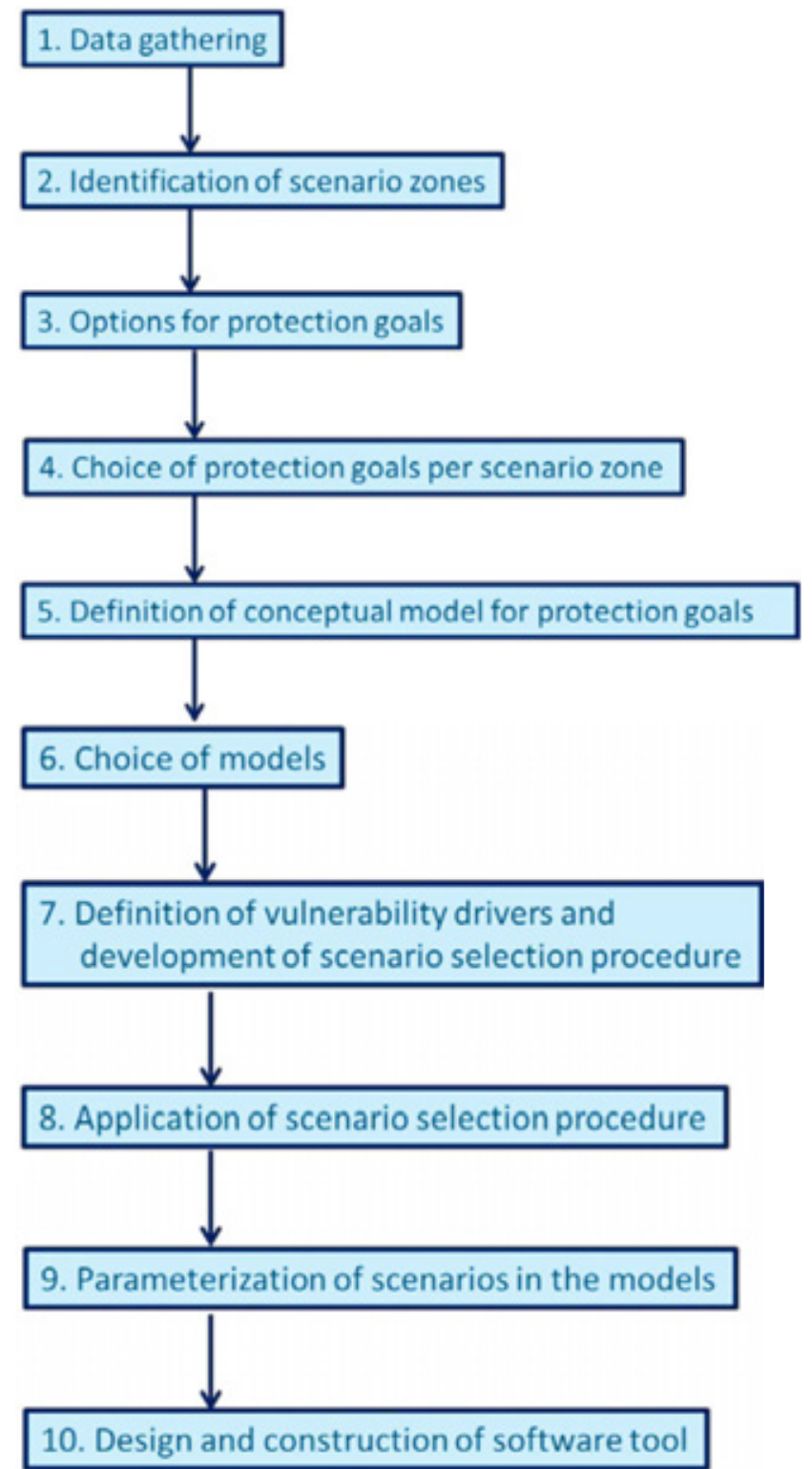

Figure 2 Roadmap for developing scenario.

In the sixth step simulation models for calculating the exposure concentrations are selected. Selection criteria may include the availability of needed input parameters (e.g. soil profiles), the need to model a certain entry route of pesticide, the access to the source code of the model, thus enabling adaptation of the model to the specific needs of the project, the use of the model elsewhere in the world, the user-friendliness, etc.

In the seventh step the vulnerability drivers are determined, and the scenario selection procedure is designed. Ideally the exposure concentrations can be calculated as a function of time and space across the relevant geographic areas by a fate model incorporating all relevant processes and which is supplied with a comprehensive data set of input data, that expresses the variability in time and space. A chosen percentile of vulnerability may be obtained by statistical manipulation of the exposure concentrations. In reality a simplified procedure is often used, where variability in time and space are considered separately. First, sensitivity drivers are identified, i.e. model input having a large effect on the selected model output. Next, a limited set of vulnerability drivers are selected from among the sensitivity drivers. Vulnerability drivers define part of the agro-environmental conditions of the scenario and are strongly spatially variable. Next, the probability in space of the vulnerability driver can be determined and this is combined with the probability in time (by including time series of the most important sensitivity and vulnerability drivers in the model calculations). In this way a simplified scenario selections procedure is designed. As sensitivity and vulnerability drivers may not only consist 
of agro-environmental data, but also be model-specific as well as interact with compound properties, expert judgement is necessary in the design of the scenario selection procedure.

Step eight consists of the application of the scenario selection procedure. For each specific protection goal and scenario zone the designed scenario selection procedure need to be worked through and this results in the final location of each specific protection goal in each scenario zone.

In the ninth step the scenarios are parameterised in the selected models. To do so, data need to be gathered for the selected scenario locations and in addition to the geographically distributed data used in step seven more detailed data are sometimes needed as input for the models. Sometimes also time series are needed for additional input data, not considered in the scenario selection procedure. Once the scenarios are ready, it is advisable to perform a number of example simulations to check the correctness of the calculations as well as the plausibility of the results.

Finally, we strongly advise to include a tenth step, aimed at the design and construction of a userfriendly software tool. In this way all simulations can be executed in a robust, transparent and reproducible way, which is important in pesticide registration procedures. 


\section{Registration by equivalence}

\subsection{Introduction}

Registration based on equivalence is conducted if the pesticide submitted for registration can be shown to be equivalent to a similar pesticide that has already been registered in the country. Two pesticides are considered equivalent if the impurity and toxicological profiles, as well as the physical and chemical properties, of the technical materials originating from different manufacturers are similar, and therefore can be expected to present similar levels of risk (FAO/WHO, 2016).

An equivalence assessment is conducted to verify whether a pest control product newly submitted for registration is equivalent to an already registered product, so that the hazards can be considered the same to that already registered product. As the first product has been fully evaluated, human and environmental risk assessments can be simplified or waived for a subsequent equivalent product. A confirmation of biological efficacy will be needed, however.

\subsection{Equivalence evaluation of chemical pesticides}

Guidance on equivalence determination found in Chapter 3.2 of the Manual on development and use of FAO and WHO specifications for pesticides (FAO/WHO 2016) and its amendments, is followed ${ }^{5}$. The applicant should use 'Form_A4_Generic_Pesticide_Application' which can be downloaded from the PCPB website ${ }^{6}$. Equivalence evaluation is based upon the Technical Grade Active Ingredient (TGAI).

It is recommended that the PCPB drafts guidance on the equivalence procedure specific for Kenya to be added to the future complete pesticide evaluation manual. Therefore, it is recommended that the present data requirements for the equivalence procedure ("Form_A4_Generic_Pesticide_Application") are brought in line with the data requirements of the FAO/WHO equivalence method (FAO/WHO 2016).

\subsection{Equivalence evaluation of microbial pest control agents}

Ter Horst et al. (2019) provides guidance for the equivalence evaluation of chemical pesticides. There is no impediment for implementing the guidance.

\footnotetext{
${ }^{5}$ Note that the Training Manual published by WHO and FAO contains practical examples of how to conduct an equivalence evaluation (Website:

http://www.fao.org/fileadmin/templates/agphome/documents/Pests_Pesticides/eng_Participant_guide_pesticide_specifica tion.pdf; last entered October 3, 2019).

${ }^{6}$ The A4 applications form on generic pesticide application can be downloaded from the PCPB website:

http://www.pcpb.go.ke/application-forms/; last entered October 25, 2019.
} 


\section{References}

Adriaanse, P.I., M.M.S. Ter Horst, B.M. Teklu, J.W. Deneer, A. Woldeamanuel and J.J.T.I. Boesten, 2015. Development of scenarios for drinking water produced from groundwater and surface water for use in the pesticide registration procedure of Ethiopia. Wageningen, Alterra Wageningen UR (University \& Research centre), Alterra report 2674. (Website:

https://library.wur.nl/WebQuery/wurpubs/fulltext/346426; last entered September 30, 2019).

Brock T.C.M., Bhatta R., Van Wijngaarden R.P.A., Rico A. 2016. Is the chronic Tier-1 effect assessment approach for insecticides protective for aquatic ecosystems. Integrated Environmental Assessment and management. DOI 10.1002/ieam.1719.

Daam M.A. and Van den Brink P.J. 2010. Implications of differences between temperate and tropical freshwater ecosystems for the ecological risk assessment of pesticides Ecotoxicology 19:24-37. DOI 10.1007/s10646-009-0402-6.

EFSA Scientific Committee. 2016. Guidance to develop specific protection goals options for environmental risk assessment at EFSA, in relation to biodiversity and ecosystem services. EFSA Journal 2016;14(6):4499, 50 pp. doi:10.2903/j.efsa.2016.4499

EFSA PPR Panel (EFSA Panel on Plant Protection Products and their Residues), 2013. Guidance on tiered risk assessment for plant protection products for aquatic organisms in edge-of-field surface waters. EFSA Journal 2013;11(7):3290, 268 pp.doi:10.2903/j.efsa.2013.3290

FAO. 2019. FAO Pesticide Toolkit. (Website: http://www.fao.org/pesticide-registration-toolkit/en/; last entered October 1, 2019).

FAO/WHO. 2016. Manual on development and use of FAO and WHO specifications for pesticides, second revision of the $1^{\text {st }}$ edition, $3^{\text {rd }}$ revision. FAO/WHO Joint Meeting on Pesticide Specifications (JMPS), WORLD HEALTH ORGANIZATION, FOOD AND AGRICULTURE ORGANIZATION OF THE UNITED NATIONS, Rome (Website: http://www.fao.org/agriculture/crops/thematicsitemap/theme/pests/jmps/manual/en/ : Last entered November 2, 2019).

FOCUS. 1996. Surface water models and EU registration of plant protection products. Final report of the work of the Regulatory Modelling Workingh Group on Surface Water Models of FOCUS (Forum for the Co-ordination of pesticide fate models and their Use). DG Sanco, 6476/VI/96, 24.2.97; $218 \mathrm{pp}$.

FOCUS. 2001. FOCUS Surface Water Scenarios in the EU Evaluation Process under 91/414/EEC. Report of the FOCUS Working Group on Surface Water Scenarios, EC Document Reference SANCO/4802/2001-rev2.245 pp.

OECD. 2018. Working Document on the Risk Assessment of Secondary Metabolites of Microbial Biocontrol Agents. ENV/JM/MONO(2018)33. (Website:

http://www.oecd.org/officialdocuments/publicdisplaydocumentpdf/?cote=env/jm/mono(2018)33\& doclanguage $=e n$; last entered October 11, 2019).

SANCO/0253/2008_rev.2. Guidance Document on the assessment of new isolates of baculovirus species already included in Annex I of Council Directive 91/414/EEC (Website:

https://ec.europa.eu/food/sites/food/files/plant/docs/pesticides_aas_guidance_baculovirus.pdf; last entered May 21, 2019).

Sumon, K.A., Ritika, A.K., Peeters, E.T.H.M., Rashid, H., Bosma, R.H., Rahman, M.S., Fatema, M.K., Van den Brink, P.J., 2018. Effects of imidacloprid on the ecology of sub-tropical freshwater microcosms. Environ. Pollut. 236, 432-441. https://doi.org/10.1016/j.envpol.2018.01.102.

Ter Horst, M.M.S., Wipfler, E.L., Adriaanse, P.I., Boesten, J.J.T.I., Fait, G., Li Wenjuan and Tao Chuanjiang, 2014. Chinese scenarios for groundwater leaching and aquatic exposure. Development of scenarios for environmental risk assessment procedures of pesticides in China, Wageningen, Alterra Wageningen UR (University \& Research centre), Alterra report 2559. (Website: https://edepot.wur.nl/318998; last entered September 30, 2019).

Ter Horst, M.M.S., Aluoch, J.A., Barasa, M.W., Bosman-Hoefakker, S., Broeders, J., Van Etten, J., De Jong, E., Ngaruiya, P.N., Steenbergh, A., Van der Valk, H., Wagate, G., Wambugu S.M., Waswa, M.N., Wipfler, E.L. 2019. Guidance on dossier evaluation for the registration of pest control products in Kenya. Wageningen, Wageningen Environmental Research, Report 2979. 
US-EPA (United States Environmental Protection Agency). 2012. Microbial Risk Assessment Guideline: Pathogenic Microorganisms with Focus on Food and Water. EPA/100/J-12/001. (Website: https://www.epa.gov/sites/production/files/2013-09/documents/mra-guideline-final.pdf; last entered October 3, 2019). 


\section{Annex 1 Correlation table between crops in the EFSA AOEM model and key Kenyan crops}

Note that the Kenyan crops still to be entered in the table below. Here only examples are given.

Table 7 Correlation table between crops in the EFSA AOEM model and key Kenyan crops.

\begin{tabular}{|c|c|c|c|c|}
\hline \multirow[t]{2}{*}{ Crop type in EFSA OPEX model } & \multirow[t]{2}{*}{ Activity (for worker exposure) } & \multirow{2}{*}{$\begin{array}{l}\text { hours per } \\
\text { day (for } \\
\text { worker } \\
\text { exposure) }\end{array}$} & \multicolumn{2}{|c|}{$\begin{array}{l}\text { Corresponding Kenyan crops } \\
\text { and crop types }\end{array}$} \\
\hline & & & $\begin{array}{l}\text { For operator } \\
\text { exposure } \\
\text { (ref. crop } \\
\text { structure) }\end{array}$ & $\begin{array}{l}\text { For worker } \\
\text { exposure (ref. } \\
\text { activity) }\end{array}$ \\
\hline Bare soil & NA & NA & Bare soil & NA \\
\hline Low berries and other small fruits & Reaching, picking & 8 & & \\
\hline Brassica vegetables & Reaching, picking & 8 & & \\
\hline Bulb vegetables & Reaching, picking & 8 & & \\
\hline Cane fruit & Searching, reaching, picking & 8 & & \\
\hline Cereals & Inspection, irrigation & 2 & Maize & $\begin{array}{l}\text { Maize } \\
\text { (also manual } \\
\text { harvesting, so } \\
\text { EFSA may } \\
\text { underestimate } \\
\text { worker } \\
\text { exposure }\end{array}$ \\
\hline Citrus fruit & Searching, reaching, picking & 8 & Citrus fruit & Citrus fruit \\
\hline Fruiting vegetables & Reaching, picking & 8 & & \\
\hline Grapes & Hand harvesting & 8 & & \\
\hline Grassland and lawns & Inspection, irrigation & 2 & & \\
\hline Golf course, turf or other sports lawns & Maintenance & 8 & & \\
\hline Hops & Inspection, irrigation & 2 & & \\
\hline Leaf vegetables and fresh herbs & Reaching, picking & 8 & & \\
\hline Legume vegetables & Reaching, picking & 8 & & \\
\hline Oilfruits & Searching, reaching, picking & 8 & & \\
\hline Oilseeds & Inspection, irrigation & 2 & & \\
\hline Ornamentals & Cutting, sorting, bundling, carrying & 8 & $\begin{array}{l}\text { Ornamentals } \\
\text { Cotton } \\
\text { (similar } \\
\text { structure) }\end{array}$ & $\begin{array}{l}\text { Ornamentals } \\
\text { Cotton (mainly } \\
\text { inspection \& } \\
\text { harvesting, so } \\
\text { EFSA may } \\
\text { overestimate } \\
\text { exposure }\end{array}$ \\
\hline Pome fruit & Searching, reaching, picking & 8 & & \\
\hline Root and tuber vegetables & Inspection, irrigation & 2 & & \\
\hline Stone fruit & Searching, reaching, picking & 8 & & \\
\hline Tree nuts & Searching, reaching, picking & 8 & & \\
\hline
\end{tabular}




\section{Annex 2 Some details for risk assessment for aquatic organisms in the EU}

Protection goals - Ecological Threshold option \& Ecological Recovery Option

To ensure ecosystem services, taxa representative for aquatic key drivers identified need to be protected at the population level. However, EFSA (2013) proposed to protect aquatic vertebrates (fish, amphibians) at the individual (in the acute RA to avoid visible mortality) to population level (chronic RA). For key drivers in edge-of-field surface waters that need to be protected at the population level or higher, EFSA (2013) presents assessment schemes that allow derivation of RACs ${ }^{7}$ on the basis of two options:

\section{Ecological Threshold Option (ETO)}

- Accepting only negligible effects on populations of aquatic non-target organisms in edge-of-field water bodies

- All tiers can address ETO

\section{Ecological Recovery Option (ERO)}

- Accepting some population level effects if ecological recovery takes place within an acceptable time

- Focus on vulnerable populations of aquatic organisms

ERO may be addressed by mesocosm experiments and effect models. To specify the protection goal in more detail EFSA (2013) uses the following terminology: 'specific protection goal' and 'exposure assessment goal'.

\section{Effect assessment}

\section{Tiered approach in the effect assessment}

Corner stone of the EU effect assessment methodology is the tiered approach. Figure 3 shows how this tiered approach is elaborated in terms of RACs and PECs.

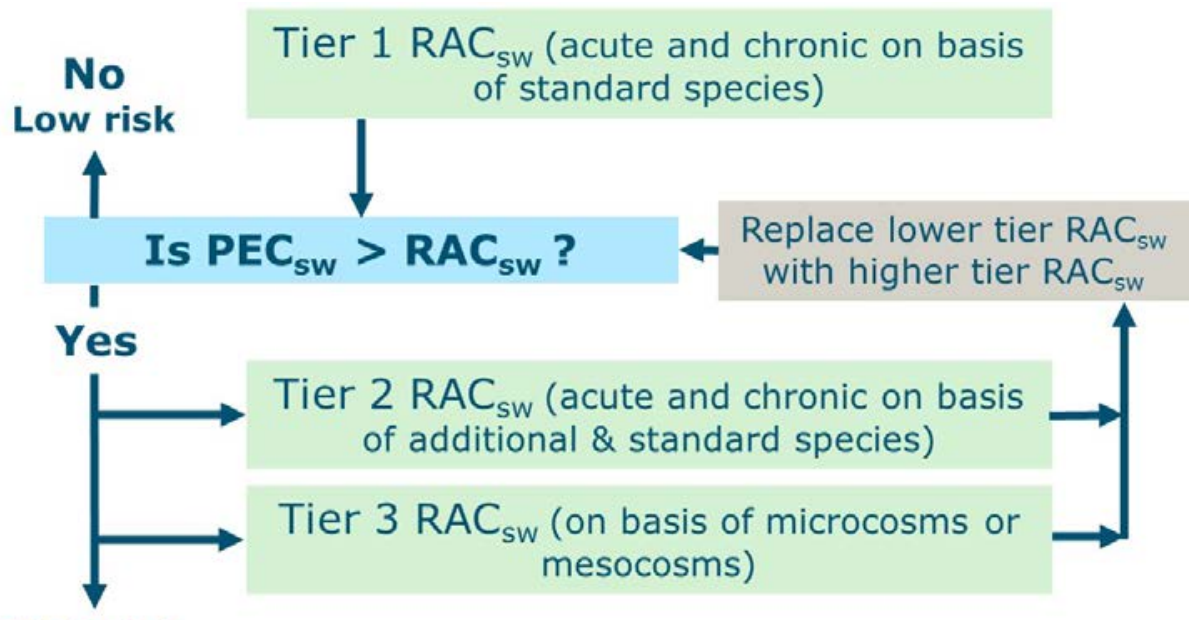

High risk

Figure 3 Summarizing the EU tiered approach in terms of PECs and RACs.

\footnotetext{
7 The results of the effect assessment are so-called Regulatory Acceptable Concentrations (RACs). For the risk assessment a RAC is linked to a PEC. The RAC is defined as the toxicity endpoint divided by an Assessment Factor (AF; also called a safety factor).
} 


\section{Tier-2 in the EU}

In case a low risk cannot be established in the first tier, supplementary laboratory toxicity studies may be used. These data are used to reduce uncertainty in the risk assessment, mainly by addressing more realistic exposure profiles and/or better capturing of inter-species variations in sensitivity.

Three options are available in the second tier (laboratory tests with additional species or refined exposure):

- 2A geometric mean - AF approach

- 2B Species sensitivity distribution

- 2C Refined exposure

Tier 2A: Geometric mean - AF approach

The Geometric mean - AF approach is used in case the number of available toxicity data is not high enough to apply the SSD approach (i.e. Tier 2B). More specific, the Geometric mean - AF method is applied for those cases where:

- $<8$ plant/invertebrate species laboratory toxicity data available

- $<5$ fish/vertebrate species laboratory toxicity data available

(see Table 26 in EFSA, 2013 for more details).

For these situations, it is proposed to calculate the geometric mean of the available toxicity values within a taxonomic group and for the same/similar endpoint (L(E)C50 or NOEC).

It is the idea that the same average level of protection can be maintained by taking the geometric mean value (rather than the lowest value) and dividing this value by the same assessment factor (AF) as used for Tier 1 (i.e. option 1 of EFSA, 2006). This approach is explained in more detail in section 8.3 of EFSA (2013).

\section{Tier 2B: Species Sensitivity Distribution approach}

Different species may respond differently to a pesticide at a given concentration. A description of this variation can be done by constructing a statistical distribution function; i.e. a Species Sensitivity Distribution (SSD). The SSD is estimated from a sample of laboratory toxicity data and visualised as a cumulative distribution function. The SSD approach is applied for those cases where:

- $\geq 8$ plant/invertebrates species laboratory toxicity data available

- $\geq 5$ fish/vertebrate species laboratory toxicity data available

SSDs are used to calculate the concentration at which a specified proportion of species are expected to suffer direct toxic effects (EFSA, 2013). These concentrations, the hazardous concentrations, are expressed as $\mathrm{HC}_{\mathrm{x}}$ values and represent the value that affects a specific proportion ( $\mathrm{x} \%$ ) of species (EFSA, 2013). In EU pesticide registration usually the $\mathrm{HC}_{5}$ is used, the hazardous concentration to $5 \%$ of the species tested (Figure 4). 


\section{Species Sensitivity Distribution (SSD) method}

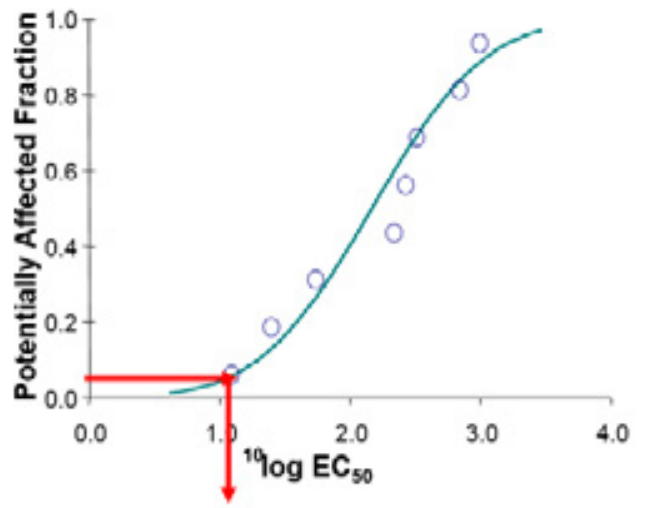

HC5

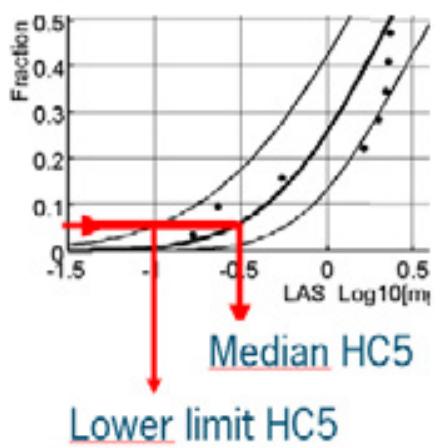

HC5 $=$ Hazardous Concentration to $5 \%$ of the species tested

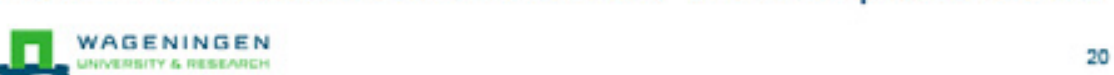

Figure 4 Graphical presentation of the species sensitivity distribution curve, its $90 \%$ confidence interval (graph on the right hand side), and as red arrows the derivation of the lower limit, median and upper limit hazardous concentration to $5 \%$ of the species (HC5).

SSDs used in risk assessments should always be constructed using toxicity data for the most sensitive taxonomic group (i.e. fish, invertebrates or primary producers) (EFSA, 2013). This means that usually arthropods are used for insecticides, primary producers are used for herbicides, but all groups are used for many fungicides. Toxicity data of species from different habitats and from different geographical regions can be combined

The RAC-SSD is derived as follows:

Vertebrates:

- Median $\mathrm{HC}_{5} / 3$ (based on NOEC/LC 10 ) or

- Median $\mathrm{HC}_{5} / 9$ (based on LC 50 )

Invertebrates:

- Median $\mathrm{HC}_{5} / 3$ or 6 (based on LC/EC 50 )

- The SSD approach is explained in more detail in section 8.4 of EFSA (2013).

Tier 2C: Refined exposure

This option was not further elaborated as this is option becomes only relevant once for Kenya (or the EAC region) specific exposure concentrations can be estimated. More information however can be found in Chapter 9 of EFSA (2013).

\section{Tier-3}

The third tier comprises derivation of RACs from model ecosystems (i.e. micro-or mesocosms).

Model ecosystems are constructed artificially with samples from, or portions of, natural ecosystems. They are usually housed in artificial containers or enclosures. Compared to natural ecosystems they are characterized by a reduction in size and complexity. The model ecosystems should include an assemblage of organisms representing several trophic levels (primary producers, herbivores, carnivores, decomposers) and the community should be 'adapted' to and in 'equilibrium' with its ambient environment. 
The advantage of micro- and mesocosm studies over the other types of experimental higher-tier studies (e.g. additional laboratory toxicity tests to construct SSDs; refined exposure studies) is their ability to integrate more or less realistic exposure regimes with the long-term assessment of endpoints at higher levels of biological integration (population- and community-level effects), and to study intraand inter-species interactions and indirect effects in a more or less realistic community (EFFSA, 2013). EFSA (2013) provides detailed guidance on designing and evaluating model ecosystem (micro/mesocosm) studies.

Once the micro-/mesocosm study is considered reliable to use in the effect assessment of the pesticide product under evaluation the concentration-response relationships should be evaluated. EFSA (2013) provides effect classes to summarise the concentration-response relationships of micro/mesocosm experiments (5). Furthermore, EFSA (2013) presents proposals for 1) the derivation of the $\mathrm{RAC}_{\mathrm{sw} \text {; }}$ (triggered by the tier 1 chronic core data) addressing the ETO for edge-of-field surface waters on the basis of appropriate micro-/mesocosm experiments and 2) the derivation of the $\mathrm{RAC}_{\mathrm{sw} ; \mathrm{ac}}$ (triggered by tier 1 acute core data) addressing the ERO on the basis of an appropriate micro/mesocosm experiment (Figure 5).

Table 8 Effect classes to summarise the concentration-response relationships of micro-/ mesocosm experiments according EFSA (2013).

\begin{tabular}{ll} 
Effect class & Description \\
Class 1 & no treatment-related effect \\
\hline Class 2 & slight effect (on an isolated sampling) \\
\hline Class 3A & pronounced short-term effect, total effect period $<8$ weeks \\
\hline Class 3B & pronounced short-term effect, recovery period $<8$ weeks after last application \\
\hline Class 4 & pronounced effect, recovery time unknown \\
\hline Class 5A & pronounced long-term effect $(>8$ weeks) but recovery demonstrated. \\
\hline Class 5B & pronounced long-term effect $(>8$ weeks) and recovery not demonstrated.
\end{tabular}

\begin{tabular}{|c|c|c|}
\hline & $\begin{array}{l}\text { AF for ETO- } \\
\text { RAC }_{\text {sw }} \text { derivation }\end{array}$ & $\begin{array}{l}\text { Field exposure concentration to } \\
\text { compare with the } \mathrm{RAC}_{\mathrm{sw}}\end{array}$ \\
\hline $\begin{array}{l}\text { Effect class } 1 \\
\text { concentration }\end{array}$ & 2 & $\begin{array}{l}\text { Acute risk: } \mathrm{PEC}_{\text {sw;max }} \\
\text { Chronic risk: } \mathrm{PEC}_{\text {sw;max }} \text { or } \mathrm{PEC}_{\text {sw:twa }}\end{array}$ \\
\hline $\begin{array}{l}\text { Effect class } 2 \\
\text { concentration }\end{array}$ & $2-3$ & $\begin{array}{l}\text { Acute risk: } \mathrm{PEC}_{\text {sw,max }} \\
\text { Chronic risk: } \mathrm{PEC}_{\text {sw;max }} \text { or } \mathrm{PEC}_{\text {sw,twa }}\end{array}$ \\
\hline \multicolumn{3}{|c|}{$\begin{array}{l}\text { Effect class } 1=\text { no treatment-related effect on sensitive endpoints } \\
\text { Effect class } 2=\text { slight effect (isolated sampling) on most sensitive endpoint }\end{array}$} \\
\hline \multicolumn{3}{|c|}{ Ecological recovery option } \\
\hline & $\begin{array}{l}\text { AF for ERO- } \\
\text { RAC }_{\text {sw }} \\
\text { derivation }\end{array}$ & $\begin{array}{l}\text { Field exposure concentration to } \\
\text { compare with the } \mathrm{RAC}_{\mathrm{sw}}\end{array}$ \\
\hline $\begin{array}{l}\text { Effect class } 3 \mathrm{~A} \\
\text { concentration }\end{array}$ & $3-4$ & $\begin{array}{l}\text { Acute risk: } \mathrm{PEC}_{\text {sw,max }} \\
\text { Chronic risk: } \mathrm{PEC}_{\text {sw,max }} \text { or } \mathrm{PEC}_{\text {sw,twa }}\end{array}$ \\
\hline \multicolumn{3}{|c|}{$\begin{aligned} \text { Effect class } 3 \mathrm{~A} & =\text { pronounced short-term effect on most sensitive } \\
& \text { endpoint, total effect period }<8 \text { weeks }\end{aligned}$} \\
\hline
\end{tabular}

Figure 5 Proposals of EFSA (2013) for 1) the derivation of the RACsw; ch (triggered by tier 1 chronic core data) addressing the ETO on the basis of an appropriate micro-/mesocosm experiment and 2 ) the derivation of the RACsw; ac (triggered by tier 1 acute core data) addressing the ERO on the basis of an appropriate micro-/mesocosm experiment. 
Wageningen Environmental Research P.O. Box 47

6700 AA Wageningen

The Netherlands

T +31 (0)317480700

www.wur.nl/environmental-research

Wageningen Environmental Research Report 2980

ISSN 1566-7197
The mission of Wageningen University \& Research is "To explore the potential of nature to improve the quality of life". Under the banner Wageningen University \& Research, Wageningen University and the specialised research institutes of the Wageningen Research Foundation have joined forces in contributing to finding solutions to important questions in the domain of healthy food and living environment. With its roughly 30 branches, 5,000 employees and 10,000 students, Wageningen University \& Research is one of the leading organisations in its domain. The unique Wageningen approach lies in its integrated approach to issues and the collaboration between different disciplines.

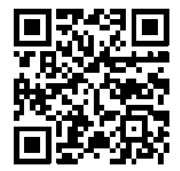





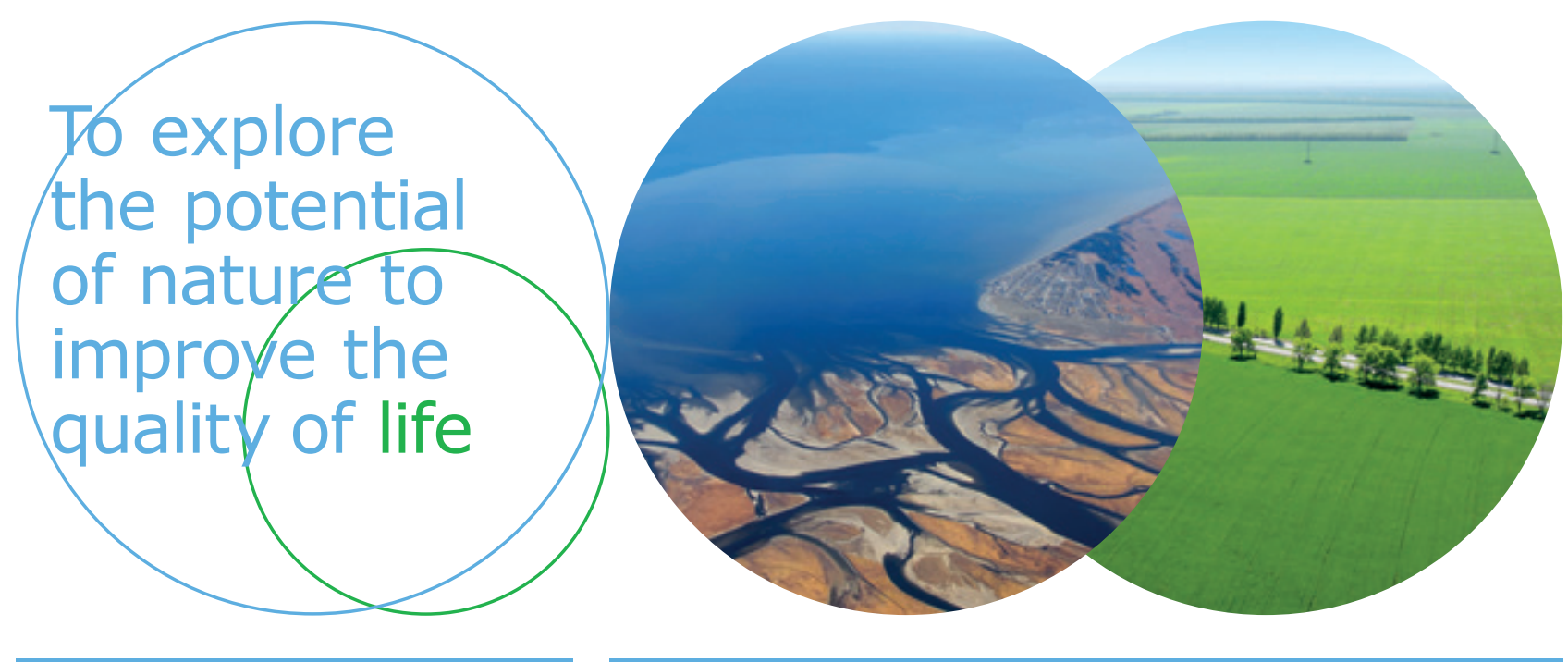

Wageningen Environmental Research P.O. Box 47

$6700 \mathrm{AB}$ Wageningen

The Netherlands

$T+31(0) 317480700$

www.wur.eu/environmental-research

Report 2980

ISSN 1566-7197
The mission of Wageningen University \& Research is "To explore the potential of nature to improve the quality of life". Under the banner Wageningen University \& Research, Wageningen University and the specialised research institutes of the Wageningen Research Foundation have joined forces in contributing to inding solutions to important questions in the domain of healthy food and living environment. With its roughly 30 branches, 5,000 employees and 10,000 students, Wageningen University \& Research is one of the leading organisations in its domain. The unique Wageningen approach lies in its integrated approach to issues and the collaboration between different disciplines. 